\title{
ПАТРОНАТ ПРОШЛОГО И ПОДХОДЯЩАЯ ИДЕНТИЧНОСТЬ
}

\section{М.Е. Шильман}

Необратимые изменения, произошедшие за последние полвека и в философии истории, и в профессиональной историографии были обусловлены, прежде всего, отказом интеллектуалов от нормативного для классической философии понятия истории как единственной и универсальной. Критическое отношение ко всякой «Большой Истории», сформировавшееся в контексте сквозного постмодернистского «недоверия к метанарративам», способствовало, в свою очередь, признанию необходимости сосуществования множества историй, не редуцирующихся к какой-либо одной процессуальной «первообразной». В целом же, отступление от исторического монизма в ходе «лингвистического поворота» привело к активизации исследований проблем, касающихся вопросов исторической эпистемологии, репрезентации прошлого и нарративного производства истории.

Новая философия истории, придающая особую значимость осмыслению процессов конструирования, освоения и присвоения прошлого свидетельствует об актуальности данного исследования, посвященного анализу отношений репрезентаций прошлого и идентификаций настоящего. С признанием способности индивида формировать свою собственную идентичность посредством исторических повествований, мы сталкиваемся с необходимостью прояснять вопрос «о пользе и вреде» множественных образов прошлого, поступающих в распоряжение современного потребителя историй.

Современное обращение к прошлому вынуждено начинаться с признания того факта, что некое гипотетическое «прошлое само по себе» в качестве универсального объекта исследования лишено логики, зна- 
чения и осмысленности. Будучи «дано» в непрозрачном, интерпретирующем языке историографии, текстуальное прошлое возникает на/в письме - как множество образов, созданных множеством историй.

Как указывает $\Phi$.Анкерсмит, историческое письмо относится по своему типу к «сложному тексту», чьи утверждения эпистемологичны, в то время как сам он-лишь репрезентативен [12, с. 423-424]. Всякая репрезентация прошлого существует и имеет значение лишь в контексте множества подобных ей и конкурирующих с ней репрезентаций, каждая из которых суть и исторический текст, и образ прошлого. Множественность сосуществующих и перекликающихся текстовобразов прошлого, обеспечивает разнообразие историй и задает предельно открытое интертекстуальное историческое поле. В этом поле, как замечает К. Дженкинс, «нет такой вещи, как „истинная история“, [...] потому, что правда - на уровне текста (в отличие от сингулярных утверждений, фигурирующих в тексте) есть лишь неприменимый концепт» [14]. По своей природе-устройству исторический текст выступает как вещь неоднородная и сложносоставная: единичные правдоподобные (простые) утверждения о прошлом вкладываются в единое нарративное (сложное) сообщение о прошлом, которое - в отличие от своих «вложений» - заведомо сомнительно. Более того, «упаковка» разрозненных утверждений о прошлом в объединяющий их контейнер нарративного сообщения делает проблематичной и их собственную эпистемологическую номинацию. По словам К. МакКуллаха, если подобная операция сборки «делает нарративные интерпретации невероятными, то и описания отдельных исторических фактов становятся неправдоподобными» [15, с. 9]. Другими словами, недоверие по отношению к репрезентации прошлого в целом оборачивается неуверенностью в отношении утверждений о прошлом, которые она задействует.

Любому историческому тексту, отсылающему не ко всему прошлому, но лишь к его фрагменту, принципиально не хватает утвердительной силы: как репрезентация, имеющая свои пределы, он всегда не(достаточно) истинен и не(достаточно) полон. В этом смысле всякое описание-представление прошлого есть испытание своего недостатка, требующее (само)утверждения как за счет отличных от него описаний прошлого, так и за счет привечающих его в настоящем прочтений. Эта фундаментальная недостаточность нарратива хорошо просматривается в двух аспектах, которые с известной долей условности можно обозначить, как «визуальный» и «коммуникативный».

«Визуальная недостаточность» заключается в том, что каждый отдельный нарратив есть лишь определенный способ и ракурс ви- 
дения, один из возможных взглядов или углов зрения на прошлое. Как поясняет Ф.Анкерсмит, «предлагаемая в нарративе „точка зрения" определяется лишь теми частями нарратива, в которых он отличается от других нарративов» [2, с. 335], однако «чтобы было возможно знание о прошлом, требуется наличие и противоборство разных мнений» [2, с. 338], потому, что «преобладание одного взгляда на прошлое оборачивается исчезновением вообще любого взгляда на прошлое» [2, с. 336]. Исторический текст представляет прошлое как отсутствующее, как «вещь без предмета»- то есть «бросает взгляд» на него, указывает некое направление в сторону искомой вещи, будучи не в силах указать непосредственно на сам предмет. С оглядкой на множественность подобных взглядов, познаваемое прошлое возникает, как область скрещения различных указаний на него; оно образуется как вещь, с которой ассоциируется множество видов/образов, полученных под разными углами зрения. Прошлое фигурирует в своих разновидностях, как некое «образование», а его поимка во многих видах сродни процедуре локации, в которой корректные координаты и параметры обнаруживаемого объекта могут быть получены лишь при условии наличия как минимум двух локаторов, «работающих по цели». Сходную процедуру конструирования прошлого рисует и Х. Уайт, утверждающий, что исторический нарратив метафорически отсылает к вещам, которые стремится охарактеризовать, - он «указывает направление для отыскания множества образов, которые ассоциируются с этими вещами» $[17$, с. 91]. Следовательно, исторический текст не представляет собой ни метафизического взгляда, вперенного в прошлое, ни объясняющего или понимающего взгляда, направленного на прошлое. Напротив, исторический текст есть особый репрезентирующий взгляд в направлении прошлого, причем последнее возникает как оптический эффект. Этот взгляд-текст, как отмечает П. Загорин, «есть момент настоящего, несвязанный с другими подобными моментами» [18, с. 266], т. е. направленный отлично от них. Собственно, разнонаправленность исторических нарративов, умножающих разновидности прошлого и гарантирующих его многообразие, обеспечивает возможность и вариативного, и объемного восприятия прошлого. Реализация этой возможности связана напрямую с необходимостью выбора позиции, с которой наблюдаемое квалифицируется как настоящее прошлое.

«Коммуникативная недостаточность» исторического текста заключается в том, что всякий нарратив, как отправленное сообщение о прошлом, не может считаться доставленным/принятым до той поры, пока не найдется его адресат. Создаваемые историками («отправи- 
телями» сообщений о прошлом) репрезентации прошлого в связи с отсутствием гарантированного получателя являются, в определении K. Дженкинса, всегда «неудавшимися репрезентациями», что рождает непрекращающуюся необходимость «искать новые пути историзации/формирования/изображения прошлого, которые не будут выступать как предписывающие» [13, с. 377]. Нарратив, как сообщение настоящему о прошлом, прицелен: он имеет определенное направление, хотя и отправлен «на удачу» - в ту точку, которая может быть занята адресатом. Он соблазняет принимающую сторону, т. е. своего потенциального читателя, согласиться принять себя в качестве своей точки зрения на прошлое. Разумеется, определенное сообщение будет удавшимся у одного адресата и неудавшимся у другого, оставаясь не(достаточно)принятым, т. е. не общепринятым. Согласный читатель становится получателем сообения, а сообщение может считаться доставленным - как отмечает М. Кукарцева, подобное «создание событий означает создание читателя» и есть акт идентификации, формирование отношения к «образу события» [5, с. 129].

Прием определенного сообщения о прошлом есть выбор определенной точки зрения на прошлое, а значит - согласие на определенное отношение к прошлому. Относя некий образ прошлого к себе, т. е. считая его «приемлемым» и «своим», читатель не только присваивает прошлое, но и позволяет именно этому прошлому властвовать над собой. В выборе «своей» манеры взгляда на прошлое (нарратива), а тем самым вида и образа «своего» прошлого, возникает субъект «своей» истории (Я). Выбор своего прошлого и описывающих его процедур есть выбор своего настоящего, т. е. себя и предписаний своего существования. Таким образом, историческое производство вступает в сообщение с историческим потреблением; продукт (письмо) оказывается востребован, потребление (чтение) - обеспечено, а читатель - идентифицирован как потребитель этого продукта. Подобное сообщение «образа прошлого» и «образа настоящего» есть процесс взаимного восполнения недостаточности обоих образов. Можно сказать, что посредством исторического текста, устанавливая/утверждая связь («общий язык») друг с другом, оба образа взаимно объективируются - возникает и субъективно идентифицированное «историческое прошлое», и идентичная ему «историческая субъективность».

Подобное взаимообусловленное возникновение суть отказ от гегельянской мечты Р.Дж. Коллингвуда о единственном историческом мире и имеет место, как указывает А. Мегилл, в современном мире, «в котором альтернативные реальности постоянно входят в конфликт, и 
в котором множество возможных идентичностей выставлено напоказ» [6, с. 138]. Невозможность легитимирующей саму себя наррации, равно как и сомнительность всякой самоидентификации, неизбежно требует их «кооперации». Последняя проясняется П. Рикером как двухстороннее содействие. С одной стороны, непрочность идентичности обусловлена «ее сугубо неявным, предположительным, притязательным характером» [9, с. 118]. С другой стороны, «исторический дискурс заявляет о своем стремлении, своем требовании, своем притязании представлять подлинное прошлое» [10, с. 321]. Это двойное встречное притязание производит взаимовыгодный притяжательный эффект. Исторический текст притягивает к себе своего читателя, который утверждает/легитимирует его в качестве представителя «исторической реальности», а читатель получает посредством исторического текста доступ к исторической реальности, которая объективирует его в качестве «исторического субъекта». Одним словом, исторический текст старается польстить читателю; на стороне же последнего остается продемонстрировать определенное отношение к тексту.

Искушенный читатель, т. е. историк, способен и оценить историографическую добротность и «дисциплинированность»- изящество строения исторического текста и точность сингулярных утверждений о прошлом - а также определить место конкретного нарратива в том или ином тематическом поле. Будучи настроен критично к историческому произведению, он занимает свою собственную позицию относительно позиции авторской, т. е. volens-nolens задает альтернативный исторический дискурс, чем производит-идентифицирует самого себя. Можно сказать, что искушенный читатель работает преимущественно с историческим письмом в графическом режиме создания себя - в отличие от читателя неискушенного, работающего в оптическом режиме идентификации себя с историческим изображением, которое ему приглянулось. Неискушенный читатель - рядовой потребитель/пользователь «готового прошлого»- воспринимает исторический текст некритично, видя в нем законченный и готовый к употреблению продукт. Таким образом, он не относится определенным образом к тексту (т.е. не вырабатывает (свое) отношение-идентичность), но относит/не относит определенный текст к «себе». Представленные на его «суд» образ прошлого и история - независимо от историографических «показателей» представляющих их нарратива - не вызывают суждений; они могут ему нравиться или не нравиться, как картинки или видеоролики, выставленные на всеобщее обозрение. В свою очередь, искомые номинации «подлинное прошлое», «истинная история» 
и «несомненная идентичность» имеют эстетические и этические основания, т. е. присваиваются исходя не по знанию, но по усмотрению.

Представляя собой, по словам Х. Уайта, не «бесстрастное исследование событий прошлого», но повествование, которое обладает определенным «нравственным смыслом» [4, с. 260], нарратив привлекает видом на прошлое. Не обнажая, а скорее маскируя факты и аргументы в свою пользу, исторический текст, по словам Ф. Анкерсмита, не полагает, но «предлагает определенную „точку зрения“, с которой следует рассматривать прошлое» [2, с. 29]. Для того, кто эту точку зрения принимает безо всякого принуждения, прошлое видится характерным - остается лишь констатировать свое приятие или неприятие увиденного. Другими словами, остаться в пределах собственного мнения о приемлемости того, что показано (вынесено на усмотрение, представлено на суд), т. е. довериться в большей степени своему чувству прошлого. Содержательность исторического текста - с точки зрения его выбора в качестве «приемлемого»- отступает на второй план. Во-первых, как требует признать А. Данто, «невозможно описать происшедшее, не прибегая, вследствие использования языка, к тем или иным моральным оценкам» [3, с. 133]. Во-вторых, - продолжает мысль Х. Уайта В. Стрелков - нарратив «не столько воспроизводит события прошлого в виде связного рассказа о них, сколько задает модель его восприятия, наполняя ее некоторыми эмоциональными валентностями» [11, с.131]. Исторический текст не (пере)убеждает и не поучает читателя, но тревожит, вызывая те или иные эмоции. Кроме того, неявное (пред)писание нарратива апеллирует к моральным (пред)установкам/предрассудкам читателя. Следовательно, акт «выбора» нарратива в качестве объективного/правдивого будет обусловлен, фигурально говоря, балансом воздержания и вожделения. Первое определяется степенью адекватности моральной позиции читателя и моральной позиции, заявленной в нарративе; второе - тем, «насколько он привлекателен (курсив мой - М. Ш.) как оригинал прошлой реальности» [11, с. 130]. Очевидно, что в этом случае неискушенный/некритический читатель претерпевает воздействие: его увлекает история, влечет показываемое в ней прошлое, беспокоят описанные события. Идя на поводу у повествования, будучи влекомым текстом, он ощущает искомый эффект реальности.

Итак, если всякое исследование прошлого и истории не бесстрастно, а его результат, как отмечает Х. Уайт, «является местом фантазирования, или беспокойства, или надежды, или сожаления» [4, с. 258], то и субъекты историй - суть следствия и результаты тех или иных при- 
страстий, влечений и вожделений. Используя метафорическое определение $\Phi$. Анкерсмита нарративных интерпретаций прошлого, которые «походят на модели, используемые дизайнерами одежды для демонстрации достоинств своих костюмов» [1, с. 122], можно сказать, что пресловутый «исторический субъект» идентифицируется, как зритель/наблюдатель, участвующий в выбранном по своему вкусу спектакле/показе. Пользуясь заемным языком (т. е. потребляя готовое, но не интерпретируя), зритель делает вывод о приемлемости/приличии того или иного «костюма», исходя из того, как он «сидит» на модели. Если продолжить мысль П. Рикера в контексте вышеозначенного подиума, то на притязание дизайнера («каждый может надеть этот костюм») зритель отвечает притязанием не на костюм, а на модель («я есть тот, кто хорошо смотрится в этом костюме»). Другими словами, зритель примеряется к манере (смиряется с манерой) показа прошлого и усматривается в ней (становится усматриваемым ею). Смотрясь в представленное прошлое, как в зеркало с надеждой увидеть в нем «подлинного себя», он исходит не из существа дела (res), но из приглядного взгляда (vis).

Недостижимость в опыте самого прошлого в настоящем замещается возможностью испытывать вызываемое чувство (не)приязни к (не)настоящему прошлому - определяя его (не)приемлемость. Нельзя не согласиться с $\Phi$. Анкерсмитом в том, что «прошлое просто не отражается в нарративе» [2, с. 332], но изображается им. В то же время, нарратив отражает настоящее: зритель, идентифицирующий себя согласно наблюдаемому «образу прошлого», представляет собой «образ настоящего». Возможность подобного отражения обеспечивается, как замечает А. Олейников, тем, что прошлое, которое «конструируется средствами историографической оптики» представляет собой целостную картину и «вынесено на удобную для рассмотрения дистанцию» [8, с. 384]. Именно рассматривая со всеми удобствами образ прошлого, оценивая степень приятности его с виду (глазу) не индифферентный зритель/читатель (вы/у)сматривает в нем приятного на вид себя.

Подобное принятие образа (становление настоящим) есть оформление «идентичности» и образование «исторического субъекта», некий пассивный дизайн посредством ассоциации «себя» с определенным изображением. В данном случае образ прошлого играет роль эстетически привлекательной картинки-приманки, соблазняющей чувствовать себя эстетически привлекательным субъектом-с-картинки. Разумеется, и присвоенное прошлое («мое прошлое»), и идентичный ему субъект являются лишь актами, виденьями. В акте присвое- 
ния-идентификации и безвидное «ненастоящее прошлое» (как terra incognita до начала времен), и безвидный «кто-то без прошлого» (при)обретают определенный вид. Историческая субъективность, возникающая вследствие ликвидации не-образованности и без-образности чистой субъективности, получает в результате возможность «строить виды» на будущее с оглядкой на свое (не)завидное прошлое. Однако, не по своему желанию, а в соответствии с той историей, которая стала теперь для него предписывающей.

В ориентированной на мета-историческую истину классической традиции, как поясняет Й. Рюзен, «пределы интерпретации были установлены согласно моральным правилам, выступающими как в роли руководящих принципов историографической работы, так и в роли руководящих принципов понимания прошлого» [16]. Это обеспечивало принципиально и превентивно идентификацию исторического субъекта: в гегелевской модели всемирной истории-суда всякое действие субъекта было потенциально предосудительно, а любая «альтернативная идентичность» автоматически аморальна. Очевидно, что неклассическая философия истории продолжает сегодня слова Ф. Ницше о том, что «всякое прошлое достойно того, чтобы быть осужденным» [7, с. 178], неявным утверждением «всякая идентичность может быть оправдана». По отсутствию единовластия единой истории и единственной исторической реальности вопрос установления власти над собой (как над историческим субъектом) теперь представляет собой в массе не рациональный выбор прошлого/истории, но эмоциональное приятие «по подобию». При этом - как сетует Х. Уайт - эффект реальности прошлого «к несчастью для исторического письма [.. . ] гораздо более наглядно (курсив мой - М. ШІ.) создают кино или видео» [4, с. 256]. А потому выбор прошлого, истории и идентичности происходит, преимущественно, «за глаза» - т. е. с точки зрения того, насколько они, повидимому, отвечают личным претензиям и предрассудкам.

Приходится сделать достаточно неутешительный вывод, который в контексте развернутых указаний Ницше на «услуги, которые может оказать жизни история» $[7$, с. 179], будет звучать с известной долей иронии. В состоянии после «конца истории» критическое рассмотрение прошлого - «очень опасная операция, опасная именно для самой жизни» $[7$, с. 178$]$ - уступает сплошь и рядом место некритическому рассматриванию прошлого. Последнее, безусловно, воплощает в себе современные чаяния безопасности и не требует ни приложения сил, ни вынесения суждений. В отличие от активной критики, толкающей к попыткам «создать себе a posteriori такое прошлое, от которого мы 
желали бы происходить» [7, с. 179], пассивное приятие готового прошлого, в чьих декорациях мы смотрелись бы выигрышно, не нуждается ни в каком определенном желании. Желание чего-то отличного от широко предлагаемого предосудительно и таит опасность само по себе, ибо противоречит логике массового потребления, берущей за образец технологии супермаркета. В текущем «состоянии постмодерна», когда зазор между искусством и жизнью практически сошел на нет, человек отталкивается от искусства истории и ждет от нее услуг по наделению себя приемлемым для жизни, устраивающим его прошлым.

Множественный смысл подобного «устроения» кажется вполне очевидным. Прошлое устраивает субъекта в том смысле, что подходит ему, оказывается «подходящим»; оно обеспечивает его идентичностью без всякого видимого принуждения. Оно устраивает субъекта в том смысле, что конституирует его, встраивает в некий порядок отношений власти, не конфликтуя с его чувством самодовольства. Но, кроме маркитантских и терапевтических услуг, приемное прошлое руководит, определяет на службу, опекает и ограждает-т. е. играет роль предоставляющего услуги и ставящего в зависимость от себя патронапокровителя. И следует ли в таком случае нам сегодня вдогонку Ницше вести речь о клиентском отношении к прошлому и о четвертом, симпатическом способе его изучения, отсылающему к постисторическому чувству?

\section{Литература}

[1] Анкерсмит Ф. История и тропология: взлет и падение метафоры. - М. : Прогресс-Традиция, 2003.

[2] Анкерсмит $\Phi$. Нарративная логика. Семантический анализ языка историков. - М. : Идея-Пресс, 2003.

[3] Данто А. Аналитическая философия истории. - М. : Идея-Пресс, 2002.

[4] Интервъю с Хейденом Уайтом // Отечественные записки. 2006. - № 2. - С. 251-261.

[5] Кукарцева M. Опыт чтения текстов в лингвистической философии истории // Философия и общество. - 2005. - № 1. - С. 115-132.

[6] Мегилл А. Историческая эпистемология.-М.: Канон ${ }^{+}$, РООИ «Реабилитация», 2007. 
[7] Нuцше Ф. О пользе и вреде истории для жизни // Ницше Ф. Сочинения: в 2 т. - М. : Мысль, 1990. - Т. 1. - С. 159-230.

[8] Олейников $A$. Микро-история и генеалогия исторического опыта Казус. Индивидуальное и уникальное в истории. - 2006.Вып. 8. - М., 2007. - С. 379-393.

[9] Рикер П. История и истина. - СПб. : Алетейя, 2002.

[10] Рикер П. Память, история, забвение. - М. : Издательство гуманитарной литературы, 2004.

[11] Стрелков В.И. К онтологии исторического текста: некоторые аспекты философии истории Ф.Р.Анкерсмита // Философия и современные проблемы гуманитарного знания. - М., 2000.Вып. 2. - С. 123-138.

[12] Ankersmit F.R. Invitation to historians // Rethinking History.2003. - Vol. 7. - № 3. - P. 413-437.

[13] Jenkins K. On disobedient histories // Rethinking History. - 2003. Vol. 7. - № 3. - P. 367-385.

[14] Jenkins K. Re-thinking history / [Electronic resource] // Interviewed by Paul Newall. - Access mode: http://www.galilean-library.org/jenkins.html

[15] McCullagh C.B. Postmodernism and the truth of history // Historically Speaking: The Bulletin of the Historical Society. - 2005. Vol. VI. - № 3. - P. 8-10.

[16] Rüsen J. Narrativity and objectivity in historical studies / [Electronic resource] // History and the Limits of Interpretation. Rice University Farnsworth Pavilion. Symposium 15-17. March 1996. - Access mode: http: //cohesion.rice.edu/humanities/csc/conferences.cfm?doc_id $=369$

[17] White H. Tropics of Discourse: Essays in Cultural Criticism. - Baltimore: John Hopkins University Press, 1978.

[18] Zagorin P. Historiography and postmodernism: reconsiderations // History and Theory. — 1990. - № 3. - P. 263-274.

Надійшла до редакиї̈ 28 лютого 2012 р. 